\title{
Calculate the optimum slot area of elliptical microstrip antenna for mobile application
}

\author{
Ali Khalid Jassim ${ }^{1}$, Raad H. Thaher ${ }^{2}$ \\ ${ }^{1}$ Electrical Engineering Department, Al Mustansiriyh University, College of Engineering Baghdad, Iraq \\ ${ }^{2}$ College of Engineering-Al-Mustansiriyah University, Iraq
}

\section{Article Info}

Article history:

Received Mar 1, 2019

Revised Jun 27, 2019

Accepted Jul 28, 2019

\section{Keywords:}

Circular slot

Equations

Mobile application

Slot area

\begin{abstract}
Designing and analysis the antenna parameter, for the calculation optimum the slot area for a new broadband elliptical antenna for mobile application, to enhancement impedance bandwidth. Two equations have been obtained, representing the first relationship between the area of the slot and the area of the patch, and the second represents the area of the slot to the wavelength of the band frequency. The antenna was implemented and gets simulation result using CST software and manufacturing on an FR-4 material with $\varepsilon_{\mathrm{r}}=4.3, \tan (\delta)=0.002$ and the feeding line has a characteristic impedance of $50 \Omega$. The proposed antenna is operating in the bandwidth $24 \mathrm{GHz}$ and the gain (6.8) $\mathrm{dBi}$.
\end{abstract}

Copyright () 2019 Institute of Advanced Engineering and Science. All rights reserved.

Corresponding Author:

Ali Khalid Jassim,

Electrical Engineering Department,

Al Mustansiriyh University, Baghdad, Iraq.

Email: alijassim79@yahoo.com

\section{INTRODUCTION}

The microstrip is often composed of a metal piece connected to a substrate from a face called a patch and the other side is printed from a conductive material called ground. The conductor material is made of copper or any material that has high conductivity. This type of antenna is characterized by lightweight and small Its size makes it easy to use in most wireless communication devices in mechanical and military applications. There are many types of polarization, which are used in wireless communication systems, especially $5 \mathrm{G}$, to increase safety, which requires a narrow bandwidth where the radiation power increases with frequency. There are three methods used to analyze the antenna are the model transmission line, the cavity model, the full-wave model is very accurate but more complicated, the model transmission line is simpler and less precise. [1].The broadband elliptical microstrip patch antenna has been investigated in literature as follows. Mohamed B. El-Mashad, Ehab A. Hegazy [2] presents four elements $28 \mathrm{GHz}$ micro-strip patch array antenna for future 5G mobile phone applications. Mohammed H. Abu Saada designs for microstrip antennas single element and arrays at $28 \mathrm{GHz}$, where $28 \mathrm{GHz}$ is one of the standard frequencies of the $5 \mathrm{G}$ communications[3].

\section{ANALYSIS OF PROPOSED ANTENNA}

The antenna performance is mainly affected by the geometrical and electrical parameters, such as the size and position of the slots.

\subsection{Summarize Procedure Design of Slot Antenna}

Summarized for the selected slot in the designing antenna [4]: 
a) Calculate the slot length its depend on resonance frequency.

b) Calculate the waveguide size of the operating bandwidth.

c) Determine the number of slots required.

d) Determine the wavelength at the operating frequency.

e) Locating the slot position.

\subsection{Size and Position of the Slots}

The increase of the impedance matching, especially at high frequencies inserting slots with various shapes by cutting a part of the radiator resulting in this is due to changing the path of the current and the input impedance. When opening any slot, we look at the distribution of the current in the patch to widening the band or obtain the desired band. If we want to improve the gain, we open the slot in the ground.

The plane elliptical of the slot, the magnetic component of the radiated field is [5].

$$
H_{\varnothing}=\frac{\left(a_{S}+b_{S}\right) V e^{-j K_{r}}}{120 \pi \lambda r}\left[\int_{0}^{2 \pi} \cos \left(\phi-\phi^{\prime}\right) e^{j K_{a} \sin \theta \cos \left(\phi-\phi^{\prime}\right)} d \phi^{\prime}\right]
$$

Where $a_{S}$ is the major radius of the ellipse slot, $b_{S}$ is the minor radius slot, V; is the voltage across the slot, and $K=\frac{2 \pi}{\lambda}$

$$
\begin{aligned}
& \text { For }\left(a_{S}+b_{S}\right)<\frac{\lambda}{2 \pi} \\
& \text { Then } \\
& H_{\varnothing}=j \frac{V e^{-j K_{r}}}{60 r} \frac{A}{\lambda^{2}} \sin \theta
\end{aligned}
$$

Where $A=\pi a b$ is the area of elliptic.

The integral in $H_{\phi}$ can be evaluated exactly as:

$$
H_{\emptyset}=j \frac{(a+b) V e^{-j K_{r}}}{60 r} J_{1}\left(K_{a} \sin \theta\right)
$$

Where $J_{1}$ is the Bessel function of the first kind and the first order.

Determine the gain from the formula:

$$
G=10 \log \left[\frac{\text { N.slot spacing }}{\lambda_{o}}\right] d B
$$

And, Beamwidth $=50.7 \frac{\lambda_{o}}{\frac{N}{2} \cdot \text { slot spacing }}$ degrees

Where $N=$ total number of slot.

And, $\lambda_{g} / 2=$ slot spacing slot.

To calculate the slot displacement using the formula for normalized slot conductance is:

$$
\frac{G_{\text {slot }}}{G_{\text {waveguide }}}\left[2.09 \frac{\lambda_{g}}{\lambda_{o}} \frac{a_{S}}{b_{S}} \cos ^{2} \frac{\pi \lambda_{o}}{2 \lambda_{g}}\right] \sin ^{2} \frac{\pi x}{a_{S}}
$$

Where

$a_{S} \& b_{s}$ major and minor dimensions of elliptical.

$x=$ slot displacement .

Figure 1 shows the slot is configured as proposed an ellipse antenna with the FR-4 material substrate, which has $\varepsilon_{r}=4.3$ and $\mathrm{h}=1.6 \mathrm{~mm}$. The slot antenna is found by equating the space of the slot formation with the space of the cylindrical wire. The frequency of the lower edge can be found for approximately the bandwidth. In the proposed antenna, the frequency corresponding to the lower edge of the bandwidth can be roughly predicted by calculating the antenna configuration area equation with the area of the indicated cylindrical wire. Figure 2 shows the equivalent radius $(r)$ and its height $(l)$ as follows [6-9]:

$$
2 \pi r l=108.244-25 a_{s}^{2}
$$




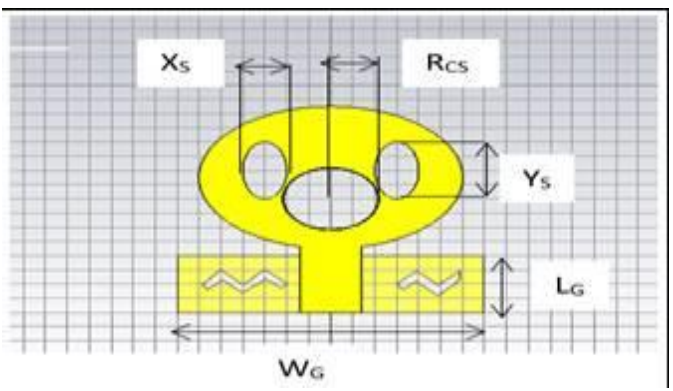

Figure 1. The Elliptic slot antenna

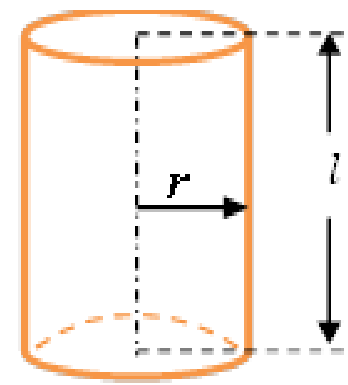

Figure 2. Cylindrical wire antenna

The input impedance of the above cylindrical wire antenna becomes a real value when its length $(l)$, which is the same as the height of the planar configuration, is made slightly smaller than that of a thin wire monopole antenna and given by.

$$
l=0.24 \lambda \frac{l}{l+r} \text { or } \lambda=\frac{l+r}{0.24}
$$

Therefore, the planar configuration is given the lower resonant frequency by[10].

$$
f_{L}=\frac{c}{\lambda}=\frac{3 \times 10^{8} \times 0.24}{(l+r)}
$$

By setting $l, a_{s}$ in (7) and substituting the resulted value of $r$ in (9), the lower resonant frequency $f_{L}$ in $\mathrm{GHz}$ becomes:

$$
f_{L}(G H z)=\frac{7.2}{\left(a_{S}+0.4356 a_{S}\right)}
$$

where $l, r$ and $a_{s}$ Are all in centimeters.

The substrate includes the effect of relative permittivity constant, then the above equation should be modified as:

$$
f_{L}(G H z)=\frac{7.2}{\left(a_{S}+0.4356 a_{s}\right) \sqrt{\varepsilon_{\text {reff }}}}
$$

Where $\varepsilon_{\text {reff }}$ can be found and given by the equation below so represented of the dielectric substrate [11-15].

$$
\varepsilon_{\mathrm{r} \text { eff }}=\frac{\varepsilon \mathrm{r}+1}{2}+\frac{\varepsilon \mathrm{r}-1}{2}\left(1+12 \frac{\mathrm{h}}{\mathrm{w}}\right)^{-1 / 2}
$$

The area of the elliptical patch effected.

$$
A_{\text {patch }}=\left[a b \pi+\left(L_{f} \times W_{f}\right)\right]-\left[2\left(a_{s} b_{s} \pi\right)+\left(a_{s}^{2} \pi\right)\right]
$$

From the optimization dimension ellipse slot for the design used:

$$
b_{s}=2 a_{s}
$$

Then $A_{\text {patch }}=\left[a b \pi+\left(L_{f} \times W_{f}\right)\right]-\left[8\left(a_{s}{ }^{2} \pi\right)\right]$

Where, $a_{s}$ the major radius of the ellipse and circular slot, $b_{s}$ the minor radius slot.

$$
A_{\text {patch }}=108.244-25 a_{s}^{2}
$$

From the optimum elliptical patch affected area. Then the slot area is:

$$
A_{\text {patch }}=3.9 A_{\text {slot }}
$$


From (12) can be calculated $\varepsilon_{\text {reff }}$ is equal to 3.9 area slot is:

$$
A_{\text {slot }}=\frac{\left[a b \pi+\left(L_{f} \times W_{f}\right)\right]}{\varepsilon_{\text {reff }}}
$$

The slot area is calculated by (18) is $27.75 \mathrm{~mm}^{2}$

The lower edge frequency $\left(f_{L}\right)$ of the bandwidth is given by [15-20]:

$$
f_{L}(G H z)=\frac{30 \times Q}{(l+r)}
$$

Where, $Q$ is an element factor, which can take values of 0.32 for an elliptical slot, and 0.35 for the circular slot. These two values of $Q$ are tested, and the first one is found suitable for ellipse patch, therefore,

$$
f_{L}(G H z)=\frac{9.6}{\left(a_{S}+0.4356 a_{s}\right) \sqrt{\varepsilon_{\text {reff }}}}
$$

Where $l, r, a_{s}$ Are all measured in centimeters?

The main radius $\left(a_{s}\right)$ of the ellipse patch can be calculated according to (20) as $5 \mathrm{~mm}$. and the radius circular slot is:

$$
f_{L}(G H z)=\frac{10.6}{\left(a_{S}+0.4356 a_{S}\right) \sqrt{\varepsilon_{\text {reff }}}}
$$

From (20) can be calculated the lower frequency also impose the highest frequency and then found the bandwidth so that finding the wavelength is $12.5 \mathrm{~mm}$.

$$
\lambda_{o}=\frac{C_{o}}{B W}
$$

Where $B w=\mathrm{F}_{\mathrm{H}}-\mathrm{F}_{\mathrm{L}}, \lambda_{o}$ The wavelength in free space, $C_{o}$ Light velocity in free space. The compare the value wavelength with the area slot the differentiating factor is 2.22 then the slot area is

$$
A_{\text {slot }}=2.220 \lambda_{o} \mathrm{~mm}^{2}
$$

Also, the slot area is calculated by (23) is $27.75 \mathrm{~mm}^{2}$

The values circular radius patch $(a c)$ is calculated according to $(20)$ as $5.44 \mathrm{~mm}$. From the above, we conclude that the (18) and (23) make it easier to calculate the area of the slot relative to the area of the patch as well as to the value of the wavelength.

\section{GEOMETRY PROPOSE ANTENNA}

Through the results of the proposed antenna, it has been proposed to design and manufacture a single antenna working in wireless communication, especially $5 \mathrm{G}$ Mobile, which has higher specifications, where the bandwidth of $24 \mathrm{GHz}$ from (6.94 to 30.95) GHz and high gain $(6.8 \mathrm{dBi})$. FR-4 substrate with $\varepsilon_{r}=$ 4.3 has been used in designing and manufacturing an antenna for the availability of the material. Figure $3 \mathrm{a}, \mathrm{b}$ is shown the proposed antenna, and Figure 4 is shown the manufacturing antenna. The parametric design of the proposed antenna is illustrated in Table 1 and fabricated using FR-4 material with size $(17 \times 14 \times 1.6) \mathrm{mm}^{3}$.The proposed geometry is simulated with CST and the bandwidth with reflection Coefficient $\left(S_{11}\right)$ is observed shown in Figure 5 and the gain is around (6.8) dBi as shown in Figure 6. Figure 7 is shown the compares between simulation and practical results for input reflection coefficient $\left(\mathrm{S}_{11}\right)$.

Table 1. Parametric Design

\begin{tabular}{cccccc}
\hline Parameters & Values in $\mathrm{m}$ & Parameters & Values in $\mathrm{mm}$ & Parameters & Values in $\mathrm{mm}$ \\
\hline $\mathrm{L}$ & 17 & $\mathrm{~W}$ & 14 & $\mathrm{H}$ & 1.6 \\
$\mathrm{R}_{\mathrm{x}}$ & 6 & $\mathrm{R}_{\mathrm{y}}$ & 5 & $\mathrm{~W}_{\mathrm{f}}$ & 2.8 \\
$\mathrm{~L}_{\mathrm{f}}$ & 5 & $\mathrm{X}_{\mathrm{S}}$ & 1 & $\mathrm{Y}_{\mathrm{S}}$ & 2 \\
$\mathrm{R}_{\mathrm{CS}}$ & 2.2 & $\mathrm{~L}_{\mathrm{G}}$ & 4 & $\mathrm{~W}_{\mathrm{G}}$ & 14 \\
\hline
\end{tabular}




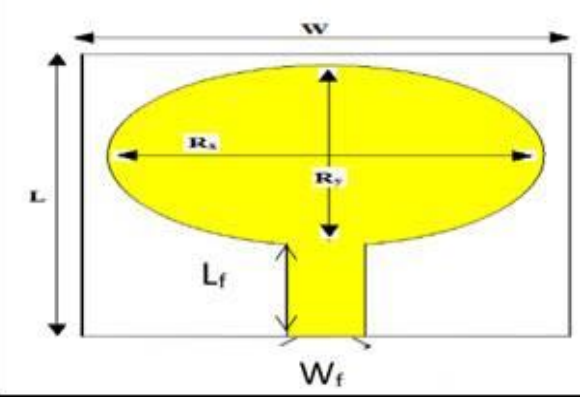

(a)

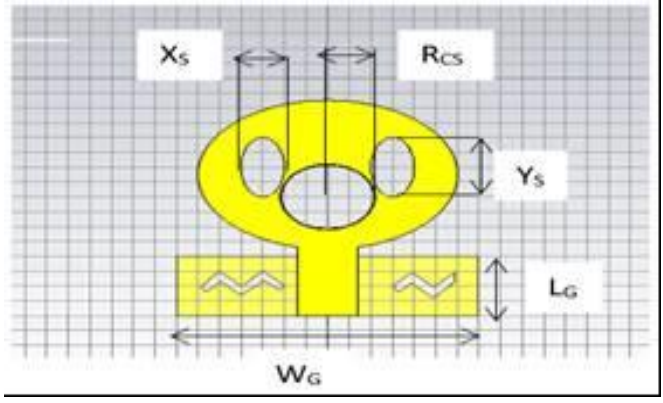

(b)

Figure 3. The Elliptic antenna (a) Prototype antenna, (b) improvement antenna Patch, microstrip and ground

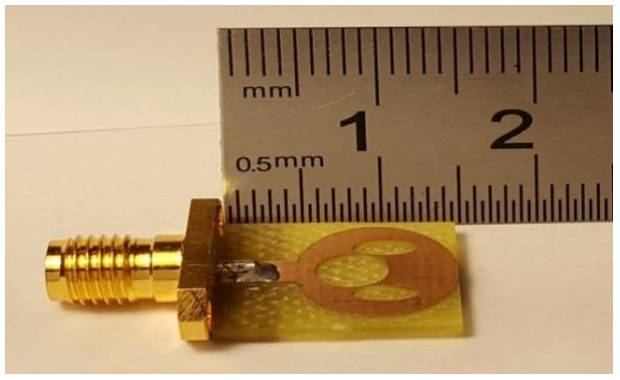

(a)

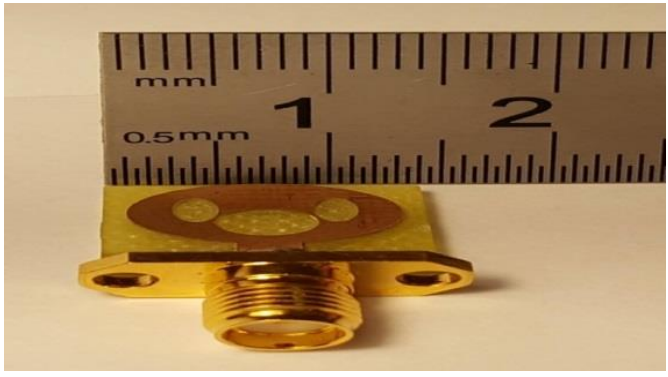

(b)

Figure 4. The practical proposed antenna

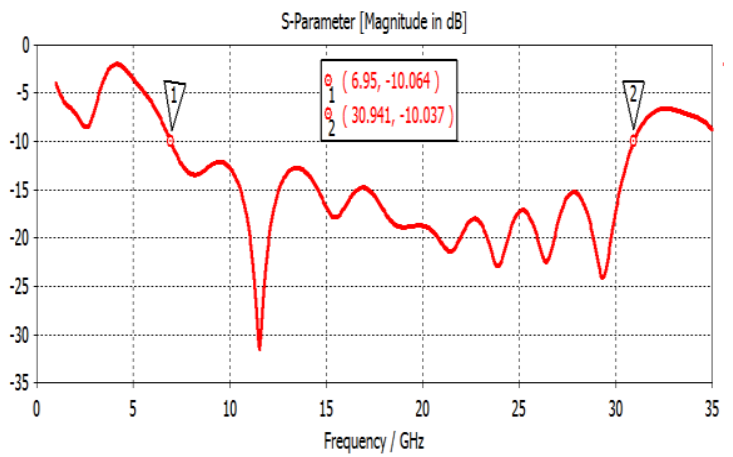

Figure 5. $\mathrm{S}_{11}$ versus frequency

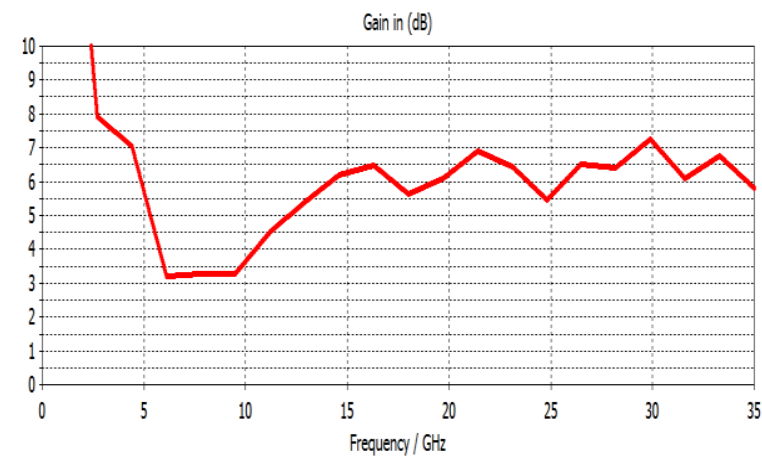

Figure 6 Gain versus frequency

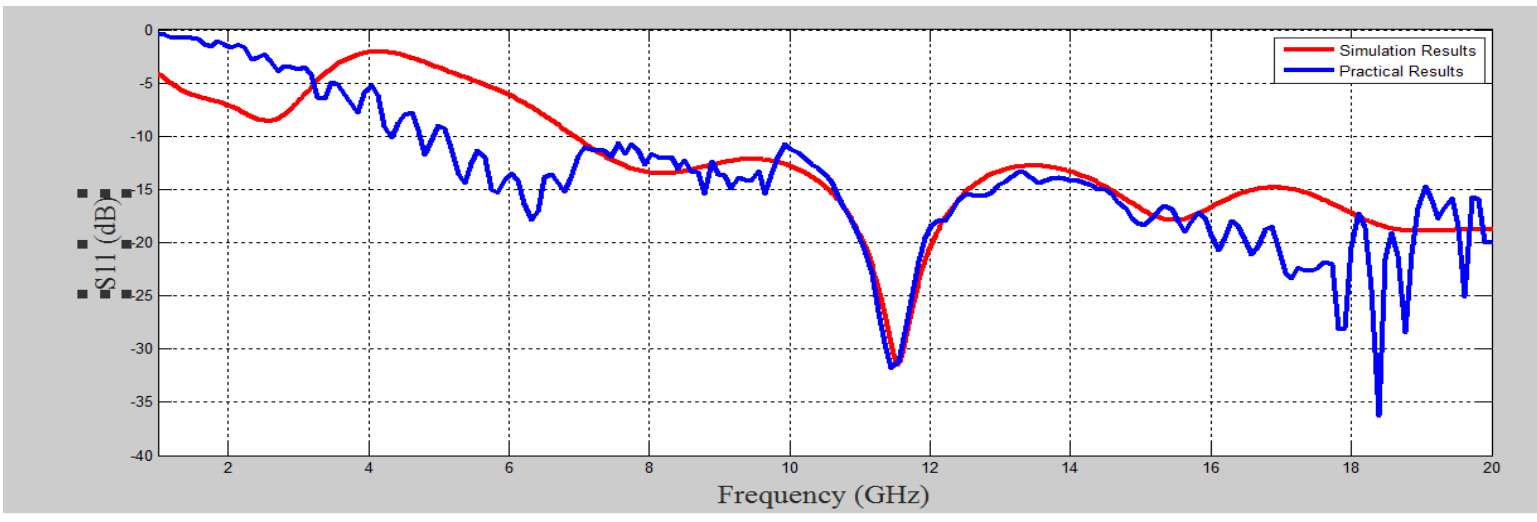

Figure 7. $S_{11}$ results of simulation and practical 
The group time delay of the antenna designed should be able to transmit the electrical pulse with minimum distortion is calculated of the proposed antenna is around to zero with variation is than $0.1 \mathrm{nsec}$ due the frequency band from $(6.95-30.94) \mathrm{GHz}$ as shown in Figure 8 and the voltage standing wave ratio (VSWR) is also less than $\leq 2$ as shown in Figure 9 so it considers as a measure for the mismatch between the line and the load. The real and imaginary parts of the input impedance are shown in Figures 10 and 11 respectively, are acceptable with the real is around $50 \Omega$ and the imaginary impedance is around zero.

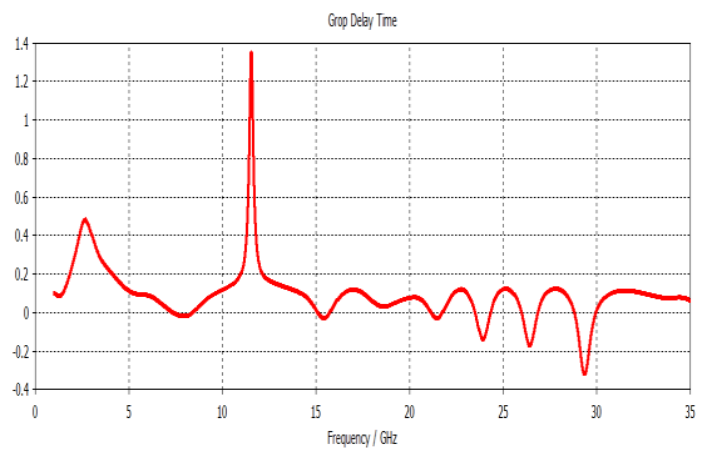

Figure 8. Group time-delay, antenna

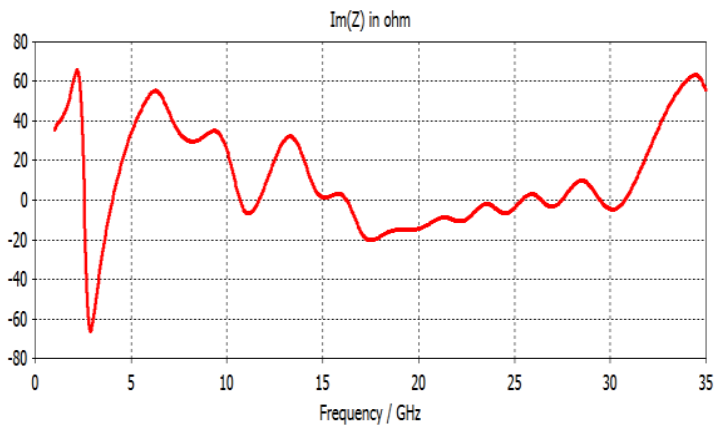

Figure 10. Imaginary impedance

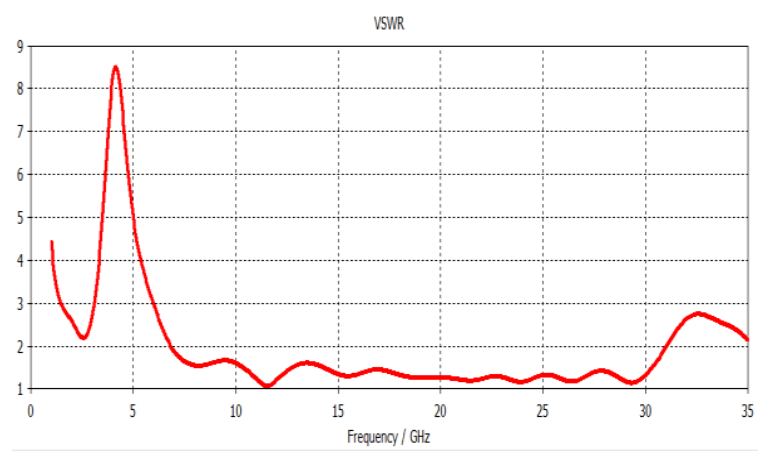

Figure 9. VSWR antenna

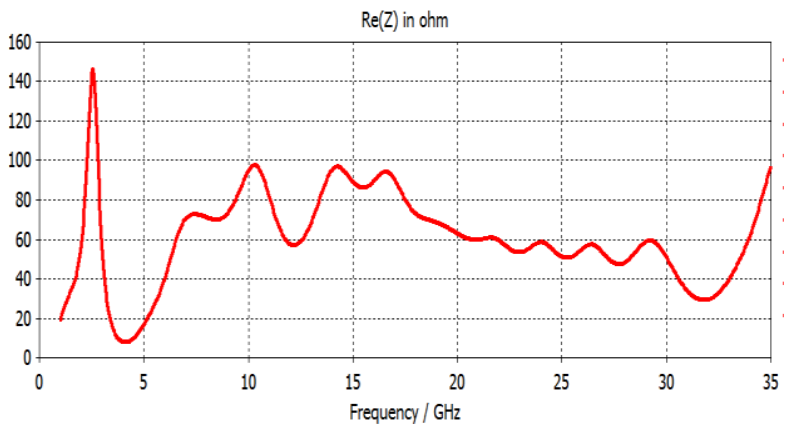

Figure 11. Real impedance

\section{CONCLUSION}

Slot antennas possess many great merits such as lightweight, very low profile, wide rate of bandwidth as well as ease of manufacturing. Then the calculated optimum the slot area for designing a proposed antenna with optimum parametric and fabricated manufactured to enhancement bandwidth. Two new equations have been obtained, representing the first relationship between the area of the slot and the area of the patch $A_{\text {slot }}=\frac{\left[a b \pi+\left(L_{f} \times W_{f}\right)\right]}{\varepsilon_{\text {reff }}} \mathrm{mm} 2$ and the second represents the area of the slot to the wavelength of the band frequency $A_{\text {slot }}=2.220 \lambda_{o} \mathrm{~mm} 2$. And the bandwidth is $24 \mathrm{GHz}$, with maximum gain $6.8 \mathrm{dBi}$.

\section{REFERENCE}

[1] C. Balanis, Antenna Theory Analysis, and Design, $3^{\text {rd }}$. John Wiley \& Sons, Inc., 2005.

[2] R. Fisher et al., "DS-UWB Physical Layer Submission to 802.15 Task Group 3a," IEEE P802.15 Working Group for Wireless Personal Area Networks, March 2004.

[3] Wonbin Hong, Kwang-Hyun Baek, and Seungtae Ko" Millimeter-wave 5G Antennas for Smartphones: Overview and Experimental Demonstration" Transactions on Antennas and Propagation, IEEE 2017.2740963.

[4] J. William and R. Nakkeeran, "A Compact Cpw-Fed Uwb Slot Antenna With Cross Tuning Stub," Progress In Electromagnetics Research C, Vol. 13, pp. 159-170, 2010.

[5] I. Oppermann, M. Hamalainen, and J. Iinatti, UWB Theory, and Applications, John Wiley \& Sons, Ltd, 2004.

[6] S. A. Fares, F. Adachi and A. Alshehri, Mobile and Wireless Communications Network Layer and Circuit Level Design, InTech Publishers, January 2010. 
[7] K. Kim and S. O. Park, "Analysis of the Small Band-Rejected Antenna with the Parasitic Strip for UWB," IEEE Transactions on Antennas and Propagation, Vol. 54, No. 6, pp. 1688- 1692, June 2006.

[8] Ali Khalid Jassim, Raad H. Thaher, "Design and Analysis of Broadband Elliptical Microstrip Patch Antenna for Wireless Communication”, TELKOMNIKA, Vol.16, No.6, December 2018, pp.2493 2500.

[9] S. Licul, J. Noronha, W. Davis, D. Sweeney, C. Anderson, and T. Bielawa, "A Parametric Study of Time-Domain Characteristics of Possible UWB Antenna Architectures," IEEE 58 ${ }^{\text {th }}$ Vehicular Technology Conference, Blacksburg, Virginia, USA, Vol. 5, pp. 3110-3114, October 2003.

[10] Ali Khalid Jassim, Raad H. Thaher," Enhancement Gain of broadband Elliptical Microstrip Patch Array Antenna with Mutual Coupling for Wireless Communication", Indonesian Journal of Electrical Engineering and Computer Science, Vol. 13, No. 1, March 2019, pp. $401 \sim 408$.

[11] J. William and R. Nakkeeran, “A Compact Cpw-Fed Uwb Slot Antenna With Cross Tuning Stub,” Progress In Electromagnetics Research C, Vol. 13, pp. 159-170, 2010.

[12] A. Othman, N. I. S. Shaari, A. M. Zobilah3, N. A. Shairi, and Z. Zakaria " Design of compact ultra wideband antenna for microwave medical imaging application", Indonesian Journal of Electrical Engineering and Computer Science, Vol. 15, No. 3, September 2019, pp. 1197 1202.

[13] Mohammed K. Al-Obaidi, Ezri Mohd, Noorsaliza Abdullah, Samsul Haimi Dahlan, and Jawad Ali, "Design and implementation of microstrip Rotman lens for ISM band applications", Bulletin of Electrical Engineering and Informatics, Vol. 8, No. 1, March 2019, pp. 90 98.

[14] Norfatihah Bahari, Mohd Faizal Jamlos, and Muammar Mohamad Isa, "Gain enhancement of microstrip patch antenna using artificial magnetic conductor", Bulletin of Electrical Engineering and Informatics, Vol. 8, No. 1, March 2019, pp. 166 171.

[15] Mohammed El Jourmi, Hassan Ouahmane, Fouad Kharroubi, “ Design and simulation of UWB microstrip patch antenna for $\mathrm{Ku} / \mathrm{K}$ bands applications" International Journal of Electrical and Computer Engineering (IJECE), Vol. 9, No. 6, December 2019, pp. 4845 4849.

[16] A. S. Abdullah and M. J. Farhan, "A novel two open terminals slot antenna for ultra wideband wireless communication applications," in Engineering Sciences-3rd Scientific Conference of Engineering Science (ISCES), 1st International Scientific Conference of, 2018, pp. 108-113.

[17] K. S. Alone and S. Prabha, "Design And B.W. Optimization Of UWB (Ultra Wideband) Antenna," International Journal Of Engineering Sciences \& Research Technology, vol. 6, pp. 284-291, 2016.

[18] A. S. A. Pingale, A. Jadhav, C. Ghanote, and U. Sonare, "Design of Elliptical Microstrip Antenna for Ultra Wide Band Applications, " pp. 276-279 2015.

[19] J. Iqbal, U. Illahi, M.I. Sulaiman, M.Alam, MS.Mazliham5, and L.S.Ding," Mutual coupling reduction in circularly polarized dielectric resonator MIMO antenna", Indonesian Journal of Electrical Engineering and Computer Science, Vol. 15, No. 1, July 2019, pp. 266 273.

[20] Siti Rohani Tajuddin, S. N. Azemi, P. J. Soh, C.B.M.Rashidi, and A Abdullah Al-Hadi," Analysis and design of directive antenna using frequency selective surface superstrate”, Indonesian Journal of Electrical Engineering and Computer Science, Vol. 14, No. 2, May 2019, pp. 529 536. 